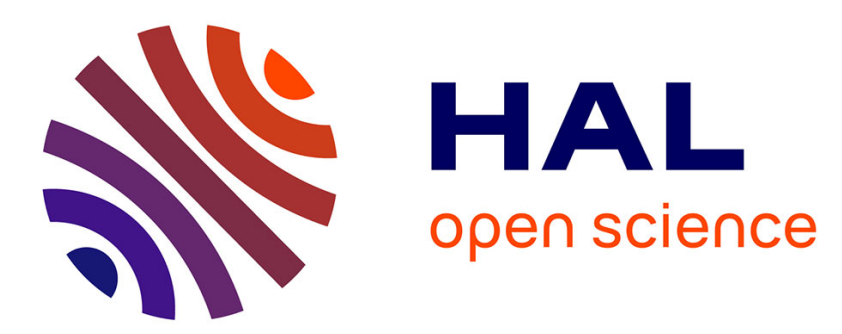

\title{
The role of associative learning process on the response of fledgling great tits (Parus major) to mobbing calls
} Mylène Dutour, Jean-Paul Léna, Adeline Dumet, Vanessa Gardette, Nathalie Mondy, Thierry Lengagne

\section{- To cite this version:}

Mylène Dutour, Jean-Paul Léna, Adeline Dumet, Vanessa Gardette, Nathalie Mondy, et al.. The role of associative learning process on the response of fledgling great tits (Parus major) to mobbing calls. Animal Cognition, 2019, 22 (6), pp.1095-1103. 10.1007/s10071-019-01301-1 . hal-02328411

\section{HAL Id: hal-02328411 https://univ-lyon1.hal.science/hal-02328411}

Submitted on 16 Nov 2021

HAL is a multi-disciplinary open access archive for the deposit and dissemination of scientific research documents, whether they are published or not. The documents may come from teaching and research institutions in France or abroad, or from public or private research centers.
L'archive ouverte pluridisciplinaire HAL, est destinée au dépôt et à la diffusion de documents scientifiques de niveau recherche, publiés ou non, émanant des établissements d'enseignement et de recherche français ou étrangers, des laboratoires publics ou privés. 
1 The role of associative learning process on the response of

2 fledgling great tits (Parus major) to mobbing calls

3

4 Mylène Dutour $^{1} \cdot$ Jean-Paul Léna $^{1} \cdot$ Adeline Dumet $^{1} \cdot$ Vanessa Gardette $^{1} \cdot$ Nathalie 5 Mondy $^{1} \cdot$ Thierry Lengagne ${ }^{1}$

$6{ }^{1}$ Université de Lyon, UMR5023 Ecologie des Hydrosystèmes Naturels et Anthropisés,

7 Université Lyon 1, ENTPE, CNRS, 6 rue Raphaël Dubois, 69622 Villeurbanne, France

8 Author for correspondence:

9 Mylène Dutour

10 mylene.dutour@hotmail.com 


\section{Abstract}

When they detect a predator, many species emit antipredator vocalizations. In some cases, they emit mobbing calls, which are associated with the caller approaching and harassing the predator while attracting others to join it. Surprisingly, although mobbing has been widely reported in adults of numerous species, there has been no test of the role of learning in mobbing call recognition, especially during ontogeny. Here, we exposed wild great tit (Parus major) nestlings to playbacks of an unthreatening, novel sound either associated with conspecific mobbing calls (experimental treatment) or with another unthreatening novel sound (control treatment). We then tested them as nestlings and fledglings to see how responses to the novel sound compared to conspecific mobbing calls. Results revealed that fledglings in the experimental treatment behaved similarly to conspecific mobbing calls and the novel sound associated with conspecific mobbing calls. Because mobbing efficiency is often linked to interspecific communication, associative learning should be used by heterospecifics as a mobbing calls recognition mechanism. Regardless of treatment during the nestling phase, fledglings always were sensitive to the playback of conspecific mobbing calls. However, fledglings from the control group were more likely to approach the loudspeaker than those from the experimental group when mobbing calls were played, suggesting that overexposure during the nestling phase altered mobbing learning. Overall, these results suggest that learning could play a role in the recognition of calls, like heterospecific mobbing calls, when paired with conspecific mobbing, and that mobbing is perceived as a threatening stimulus from a very young age.

Key words Alarm call $\cdot$ Associative learning $\cdot$ Birds $\cdot$ Communication $\cdot$ Mobbing 


\section{Introduction}

In many species of small birds and mammals, two contrasted anti-predator strategies, each associated to a specific alarm call, can be observed according to predator dangerousness: prey may flee or mob the predator (Marler 1957). Mobbing behaviour is usually exhibited when predators do not represent an immediate threat and is characterized by harassment or even attacks on the predator as well as vocalizations (i.e., mobbing calls) that quickly gather neighboring conspecifics and other prey species in the mob (Hartley 1950; Curio 1978). Both the evaluation of the threat associated with the predator and the recognition of mobbing calls, including heterospecific calls, are required to make mobbing behaviour an efficient antipredator strategy.

Associative learning is a behavioural modification following reinforcement, based on associations between two stimuli, responses and events (Shettleworth 1998; Griffin et al. 2015). This process is essential to the development of vocalizations and several behaviours such as those involved in predator avoidance (Ferrari and Chivers 2011). Animals can learn to flee after associating an unfamiliar sound (i.e., novel sound) with (i) the appearance of a model predator (birds: Magrath et al. 2015a; mammals: Shriner 1999; Wheeler et al. 2019) or (ii) the hearing of alarm calls, without having to see the callers or a predator (Potvin et al. 2018). In mobbing behaviour, there is ample evidence of a process of associative social learning between conspecific mobbing calls and predators (Curio et al. 1978a; Maloney and McLean 1995; McLean et al. 1995; Griffin and Galef 2005; McIvor et al. 2018) but in all cases the training phase was based on visual cues; individuals were trained about predators through pairing model predator presentations with a training stimulus (i.e., live conspecific demonstrator engaging in mobbing, mobbing calls paired with mounts of conspecifics, or mobbing calls alone). However, visual associative learning needs the inexperienced learner to 
be in the vicinity of the mobbing scene, so that the opportunities for learning while reducing the risk of threat may be limited, especially for species living in dense vegetation. This challenge is overcome in the case of acoustic-acoustic association, which may be efficient even when the tutor and the threat are difficult to observe, possibly resulting in the rapid spread of mobbing call recognition in natural communities.

Mobbing calls are usually characterized by loud and repetitive vocalizations, both features that should facilitate associative learning, as there is ample opportunity to hear mobbing calls while observing the threat, with less likelihood of immediate danger (Magrath et al. 2015b). In birds, such association between a predator and the expression of a mobbing behaviour could be achieved after young fledge leave their nest. In this case, young fledglings can learn from their parents and several observations are in agreement with this statement (Curio et al. 1978b; Griesser and Suzuki 2016). If nestlings however are able to associate several acoustic signals from their nest cavities (i.e., they are able to associate the mobbing calls emitted by parents with other vocalizations prevailing on a mobbing scene) they should also be able to respond to mobbing calls appropriately as soon as they leave the nest. To our knowledge, this capacity has never been investigated before. Indeed, until now, associative learning has been examined using the association of several sensory channels, especially visual and acoustic (e.g. Maloney and McLean 1995; McIvor et al. 2018). However, as outlined above, young could also associate unknown vocalizations with conspecific mobbing calls if both are simultaneously emitted in a mobbing scene. Such a mechanism could be particularly relevant in learning to recognize heterospecific mobbing calls.

The great tit (Parus major) is a well-suited species to study the ontogeny of mobbing behaviour in the wild. It is well known for its learning abilities (Exnerová et al. 2006; Cole et al. 2011; Morand-Ferron et al. 2015) and its tendency to exhibit mobbing behaviour and emit mobbing calls when confronted with a predator (Lind et al. 2005; Dutour et al. 2016; Carlson 
et al. 2017a; Kalb et al. 2019). Furthermore, this altricial species provides a good system for studying whether naïve nestlings are able to associate mobbing calls with unfamiliar stimuli in the absence of any visual cues from adults or predators in the nest cavity.

The goal of this study was to determine whether associative learning might serve as a mechanism for the development of mobbing calls recognition for free-living animals. Specifically, we investigated whether experiencing a novel stimulus associated with conspecific mobbing calls during the nestling period led great tit nestlings to associate this novel sound with mobbing during the fledgling period. We designed playback experiments in two groups: (i) an experimental group in which we trained individuals by broadcasting a novel sound (i.e., associative learning stimulus) with mobbing calls (i.e., functional stimulus) and (ii) a control group in which the associative learning stimulus was broadcast with another novel sound (hereafter control stimulus).

In line with previous work showing that nestlings cease begging when they hear playbacks of their parents' alarm calls (Davies et al. 2004; Hollén and Radford 2009; Barati and McDonald 2017), we predict that at the end of the learning period, only nestlings belonging to the experimental group should cease begging when they hear the associative learning stimulus. We also measured responses at the fledgling stage after the playback of the associative learning stimulus. We predict that the playback of the associative learning stimulus should elicit a stronger mobbing response from the experimental group compared to the control group (i.e., increases in scanning, calling and moving) because the experimental group should associate the unfamiliar sound with mobbing and respond to the unfamiliar sound as threatening, while the control group should not. Because it was important to ensure that fledglings were sensitive to mobbing, we also tested whether they responded to the playback of conspecific mobbing calls. 


\section{Material and methods}

\section{Study sites and species}

We chose great tits, a common territorial passerine which breeds in secondary holes and wooden artificial nest boxes throughout Europe and parts of Asia and North Africa (Perrins 1965). The study was conducted in the Pierre Vérots Foundation, a private natural reserve located in the south-east France $\left(4^{\circ} 91^{\prime} \mathrm{E}, 45^{\circ} 95^{\prime} \mathrm{N}\right)$. The study area covers approximately 150 ha and contains 120 nest boxes separated at minimum by $50 \mathrm{~m}$ and mainly occupied by great tits. This distance corresponds to the minimum distance separating tit territories during the breeding season in our study area and is far enough to ensure that the playbacks are not heard by neighbours (at 50 meters, the amplitude levels fluctuate from 33 to $39 \mathrm{~dB}$, obtained from the loudspeaker, Solo 01dB Metravib, Z weighting, re: $20 \mu \mathrm{m} \mathrm{Pa}$; these levels are lower than the natural background noise levels in forest areas, fluctuate from 35 to $45 \mathrm{~dB}$ in quiet situations, 52 to $70 \mathrm{~dB}$ in noisy situations). The study took place during the breeding season (April-July 2017). We visited nest boxes at least every two days from the beginning of the breeding season onwards to determine the laying and hatching dates. When nestlings were 8 days old, they were ringed with a unique combination of color bands for individual identification. Nestlings spent $19.3 \pm 1.4$ days in the nest. Nestlings from the same nest all hatched on the same day and subsequently also fledged on the same day.

\section{Experimental procedures: presentation of stimuli}

The aim of our experiment was to assess whether chicks were able to associate a novel stimulus with conspecific mobbing calls. In 120 nest boxes, 31 were unoccupied, 14 occupied 
by the blue tit (Cyanistes caeruleus) and one was occupied by the willow tit (Poecile montanus). Each of the remaining 74 nest boxes occupied by great tits was randomly assigned to one of the two treatments (balanced for laying date to ensure equal representation of both treatment groups over the breeding season). In the first treatment (38 nests), the associative learning stimulus was associated with conspecific mobbing calls (hereafter experimental group) while in the second treatment (36 nests) the associative learning stimulus was associated with unfamiliar stimulus (control sequence, hereafter control group). Behavioural tests were conducted both during the development of nestlings and the fledging day.

Playbacks were always broadcasted once adults were silent and away from the nest (at least $15 \mathrm{~m}$ ) or from the focal fledgling (at least $5 \mathrm{~m}$ ). If parents responded to playback during tests, we stopped the playback and restarted at least 30min after, but such cases were rare $(\sim 5 \%$ of total tests).

\section{Choice of experimental stimuli and playback materials}

Three kinds of stimuli were used during playback experiments. First, we used mobbing calls produced by four great tits in response to the Eurasian pygmy owl (Glaucidium passerinum) and to conspecific mobbing calls. Calls were recorded with a Fostex FR2LE digital recorder connected to a Sennheiser ME67-K6P microphone. We also used mobbing calls produced by ten great tits obtained from the Xeno Canto online database (http://www.xeno-canto.org) (see online supplement, Appendix 1). For the associative learning and the unfamiliar stimulus, we used two musical instrument sounds (clarinet and trumpet sequences) obtained from an online sound bank (http://www.universal-soundbank.com) to ensure the stimuli used had no biological value and were unfamiliar. In order to ensure that control sounds were unfamiliar, we first conduced a pilot study to assess the response of adult great tits $(n=9)$. None of them 
approached and mobbed the loudspeaker. We matched the frequency characteristics and temporal structure of the associative learning and the unfamiliar stimulus to obtain stimuli of the same duration and the same frequency bandwidth using Avisoft-SASLab Pro. For the experimental treatment, we built playbacks containing the associative learning stimulus (i.e., clarinet) with mobbing calls. For the control treatment, the associative learning stimulus was associated with the unfamiliar stimulus (i.e., trumpet) (spectrograms of mobbing calls, associative learning stimulus and unfamiliar stimulus are available in supplementary material Appendix 2 Fig. A2). Each playback track consisted of 10 seconds of associative learning stimulus followed by 10 seconds of the mobbing calls or the unfamiliar signal, and this sequence was repeated three times in order to reach one-minute in total, time used in a recent study conducted on nestling passerines in response to calls (Wheatcroft 2015). In order to avoid habituation to playbacks, we constructed 21 one-minute playback samples for each group and each sample was used only once (i.e., as nestlings spent $19.3 \pm 1.4$ days in the nest, we used one stimulus by day) (Hurlbert 1984; Kroodsma et al. 2001). Because we used mobbing calls produced by 14 great tits in total to construct 21 playback sequences, some soundtracks are therefore only imperfectly independent from other ones, but the risk of pseudoreplication was clearly minimized. We also built two additional 30-second playback samples containing associative learning stimulus or mobbing calls to test the response of nestlings and fledglings. We decided to keep the test duration shorter than was usual in previous studies conducted on adults' great tit (including our own Dutour et al. 2017b; see also Suzuki et al. 2012) in order to limit the risk of interference from parents during tests. The average amplitude used for these playbacks was obtained with a sound level meter placed $1 \mathrm{~m}$ from the loudspeaker $(83.9 \pm 3.51 \mathrm{~dB}$, mean $\pm \mathrm{SD}$, Solo 01dB Metravib, Z weighting, re: $20 \mu$ $\mathrm{m} \mathrm{Pa)}$. We broadcast sound tracks using a Shopinnov $20 \mathrm{~W}$ loudspeaker (frequency response $100 \mathrm{~Hz}-15 \mathrm{kHz})$. 


\section{Behavioural responses of nestlings}

Begging calls suppression is described as a good measure of whether nestlings interpret sounds as cues of danger (Magrath et al. 2010). To determine whether playback treatment (i.e., associative learning stimulus with unfamiliar stimulus or associative learning stimulus with mobbing calls) influenced nestling calling activity, every day, between $7 \mathrm{am}$ and $1 \mathrm{pm}$, and between hatching day and fledging day, we measured nestling production of begging calls within the nest box during 30 seconds (begging call $=1$, no begging call $=0$ ) before and after broadcasting the treatment, 1 minute being time by which passerine nestlings' behaviour return to normal (Wheatcroft 2015). To measure this behaviour, one observer was placed $50 \mathrm{~cm}$ from each nest to listen to the calls of the nestlings, which were clearly heard at short distance. Although there were multiple observers $(n=8)$ to measure begging call propensity, we did not detect an observer effect (GLMM: $P>0.05$ ). Additionally, at the end of the nestling phase, between 19 days post hatch and fledging day, begging call propensity was measured before and after playback of the associative learning stimulus. To create as natural a situation as possible, the loudspeaker was placed on the top of the nest box for all trials. The average amplitude used for the playback was obtained with a sound level meter placed in the nest boxes $(67.98 \pm 0.94 \mathrm{~dB}$, mean $\pm \mathrm{SD}$, Solo $01 \mathrm{~dB}$ Metravib $\mathrm{Z}$ weighting, re: $20 \mu \mathrm{m} \mathrm{Pa})$.

\section{Behavioural responses of fledglings}

To test whether associative learning is involved in the development of mobbing calls recognition, we studied fledglings' responses to the playback of either the associative learning stimulus alone (control: $n=30$ from 22 nests; experimental: $n=31$ from 19 nests) or the 
conspecific mobbing calls (control: $n=19$ from 14 nests; experimental: $n=26$ from 16 nests).

212 Tests were performed during the day of fledging (except 4 tests conducted the second day

213

214 after fledging corresponding to $3.8 \%$ of total tests). Each test was conducted by two field assistants. One was assigned to the soundtrack preparation and playback operation, while the other was kept unaware of the selected soundtrack (although they could hear it) and assigned to the observation of the focal bird. In all experiments and before the playback, the identity of the focal fledgling was determined using the unique leg color bands fitted to each fledgling using binoculars. Neither of the two field assistants knew whether the fledging was in the control or experimental group. Once a focal fledging was identified, the loudspeaker used to broadcast the acoustic stimulus was placed $\sim 20 \mathrm{~m}$ from the fledgling at the base of a tree at 1.5 meter high. All observations were done using binoculars. Observations were made $\sim 10 \mathrm{~m}$ from the loudspeaker and the focal fledging, a distance from which the tits' behaviour was not disturbed. Trials were conducted mostly around $12 \mathrm{am}$ (range $8 \mathrm{am}-5 \mathrm{pm}$ ) to ensure good light, in calm and dry weather. Playbacks were started when no bird was visible close to the speaker and no bird was calling. To test fledglings' responses, we recorded the following behavioural variables during the 30 s of playbacks: (i) number of horizontal scans (i.e., the number of movements that birds made with their heads from left to right or right to left), (ii) calling (i.e., producing any mobbing vocalizations; call propensity: mobbing vocalization $=1$; no mobbing vocalization $=0$ ), (iii) approaching the loudspeaker (i.e., we recorded whether birds approached within $15 \mathrm{~m}$ of the loudspeaker during playback; see Dutour et al. 2017b for more details), and (iv) fleeing (i.e., we recorded whether birds moved away more than $10 \mathrm{~m}$ from their initial position). We measured these behaviours because they are good indicators of perceived danger in birds (Curio et al. 1978a) and are common during mobbing events (Suzuki et al. 2016; Carlson et al. 2017a; Carlson et al. 2017b; Dutour et al. 2017b; Suzuki et 
al. 2017). There was 10-minute gap between playback of the associative learning stimulus and playback of mobbing calls.

\section{Data analysis}

Analyses were done using SAS 9.4 (SAS Institute Inc., Cary, NC, U.S.A.) and R v.2.15.1

softwares (The R Foundation for Statistical Computing, Vienna, Austria, http://www.rproject.org). We first examined whether begging call propensity varied between treatment groups during the nestling period. For this purpose, we analyzed call propensity recorded each day before broadcasting the treatment using a logistic linear mixed model (LLMM) for which the call propensity was treated as a repeated dependent binary variable. To this aim, nest was considered as a random effect and the correlation between successive observations recorded at the same nest was specified using an autoregressive covariance structure. The treatment group, the time elapsed since hatch (i.e., nestlings age) as well as their interactive effect, were introduced as fixed effects. The significance of each fixed effect was tested using a nonsequential $\mathrm{F}$ test and the Kenward-Roger method was used to approximate the denominator degrees of freedom (SAS 9.4). Non-significant terms were successively dropped to obtain the final model. We used a similar model framework to compare the propensity of nestlings to stop begging after the onset of the broadcasting treatment according to the treatment group and the time elapsed since hatching. For this purpose, all observations for which nestlings were not calling before the onset of the playback treatment were discarded from the analysis.

We used a Fisher exact test to test whether the begging calls propensity just after the playback of the associative learning stimulus only when nestlings were between 19 days post hatch and fledging day varied according to the group (experimental or control). 
To investigate the behavioural responses of fledglings, we first examined whether the number of horizontal scans varied between treatment groups and playback during the fledgling period ( $n=106$ ). For this purpose, we ran generalized linear mixed models (GLMM) which included the treatment group, the playback (associative learning stimulus or mobbing calls) and their interactive effect as a fixed terms and nest as a random term. We used a negative binomial error distribution and log-link function for this analysis (glmer.nb in the package lme4; Bates et al. 2014). To investigate the call propensity, we used a binomial error distribution and logit-link function (glmer in the package lme4; Bates et al., 2014) (calling response $=1$; no calling response $=0$ ). As above, nests were included in the model as a random effect. The treatment group, the playback and their interactive effect were introduced as fixed effects. For both scanning and call propensity, we further conducted pairwise comparisons (glht in the package multcomp). Finally, because approaching and fleeing behaviours (two behaviours linked to movements) were opposed to immobility behaviour (see online supplement Appendix 3, Fig. A3), all approaching and fleeing individuals were regrouped within a unique category (hereafter moving individuals) and compared to the individuals who stayed still. To compare the propensity of fledglings to move $v s$ individuals who stayed still according to treatment group and playback, we used a binomial error distribution and logit-link function. We then focused our analysis on moving individuals only (i.e., fleeing and approaching individuals; $n=23$ ). Because only a small number of fledglings moved, Fisher's exact test was used to investigate the variation in mobbing propensity (i.e., approach) according to the treatment group in response to the mobbing call playbacks $(n=17)$. Because only one of the control fledglings moved when exposed to the playback of the associative learning stimulus, we discarded this group and we used a Fisher's exact test to investigate the variation in mobbing propensity of individuals from the experimental group between the two playbacks $(n=16)$. 
Data availability The datasets generated during the current study are available from the corresponding author on request.

\section{Results}

\section{Behavioural responses of nestlings}

The calling behaviour before the broadcasting treatment did not significantly vary in function

to the time elapsed since hatching up to fledging but it was significantly higher for the

experimental group than the control group $\left(n=1420\right.$, treatment effect: $\mathrm{F}_{1,341}=4.17 ; P=0.042$ ; time effect: $\mathrm{F}_{1,426}=0.66 ; P=0.417$; interaction: $\left.\mathrm{F}_{1,425}=0.40 ; P=0.529\right)$. The propensity to stop calling after the onset of the broadcasting treatment significantly increased in function to the time elapsed since hatching but did not vary between treatment groups although call suppression tended to increase with time slightly more for the control group than for the experimental group $\left(n=353\right.$, treatment effect: $\mathrm{F}_{1,156}=0.11 ; P=0.745$; time effect: $\mathrm{F}_{1,176}=$ 46.19; $p<0.0001$; interaction: $\left.\mathrm{F}_{1,170}=3.69 ; P=0.057\right)$. We did not detect a treatment group effect on the nestlings responses to the playback of the associative learning stimulus $(n=11$; $P=0.608)$.

\section{Behavioural responses of fledglings}

Scanning was significantly affected by the interaction between the stimuli that were broadcast (associative learning stimulus or mobbing calls) and the treatment group (experimental and control) (Table 1; Fig. 1). In response to mobbing calls playbacks, the rate of horizontal scans 
did not differ between the two groups $(P=0.99$; Fig. 1$)$. It was higher during playback of mobbing calls than during playback of the associative learning stimulus for the control group $(P=0.004$; Fig. 1$)$ while it did not differ for the experimental group $(P=0.99$; Fig. 1$)$.

Similar variations were found for call propensity as indicated by a significant interaction effect between group and playback (Table 1; Fig. 2), although these variations were not statistically different between both groups in response to the associative learning stimulus playback $(P=0.95$; proportion of calling: associative learning $=22.5 \%$; control $=6.7 \%)$. Furthermore, there was a significant effect of playback on the probability of moving (i.e., approaching and flight behaviours), whereas group had no significant effect (Table 1; Fig. 3). In response to mobbing calls, fledglings were more likely to move than in response to the associative learning stimulus playback. Results indicate that (i) in response to the mobbing call playbacks, individuals from the control group were more prone to approach the loudspeaker than experimental individuals ( $n=17$; Fisher test: $P=0.049$; Fig. 3 ) (ii) approaching behaviour of individuals from the experimental group did not differ between the two playbacks ( $n=16$; Fisher test: $P=0.999$; Fig. 3 ).

\section{Discussion}

We have investigated whether nestlings submitted to a novel stimulus associated with mobbing calls enabled them to recognize this stimulus as an indicator of threat proximity when becoming fledglings. This experiment, involving classical conditioning, showed that fledglings learned to associate a novel stimuli with mobbing calls and exhibited vigilance behaviours in response to the novel stimuli whereas they do not as nestlings.

\section{Effect of the associative learning during the nestling phase}


335 Several studies have shown that nestlings become silent when they hear playbacks of their parents' alarm calls (Davies et al. 2004; Platzen and Magrath 2004; Madden et al. 2005; Haff and Magrath 2012; Barati and McDonald 2017). However, most of these studies have compared alarm calls to background noise or sympatric species stimuli (i.e., stimuli known). In the present study, nestlings suppressed calling when submitted to associative learning stimulus equally to mobbing call playbacks, suggesting that novelty (i.e., a stimulus never heard before) alone may be used as a signal of danger (Schaller and Emlen 1961; Curio et al. 1978b). We found that, contrary to young nestlings, older nestlings reduced begging calls in response to the associative learning stimulus and mobbing calls, suggesting that older nestlings are less prone to recognition errors than younger ones (Davies and Brooke 1988; Davies et al. 2004). This pattern of gradual acquisition is in accordance with previous studies conducted on nestling great tits (Rydén 1978). We did not detect a group effect on nestling' responses to playbacks of the associative learning stimulus at the end of the learning period, but the low sample size may have reduced our ability to detect a significant pattern. A detailed study of nestlings' behaviour would be insightful to actually address this question (e.g., if they crouched down inside their nest cavity, suppressed their movements, increase their heart rate and electromyographic activity after parental alarm calls; Rydén 1978; Ryden 1980; Suzuki 2011). Finally, another interesting aspect is related to the sound degradation. As we used hole nesters, a sound degradation may occur that a sound will appear different within and outside

354 the nest box. However, quite low-frequency sounds have been used in this study, with 355 probably low alteration, and the sounds were broadcast using a loudspeaker placed on the top of the nest box for all trials, with the only obstacle being the wall thickness of the nest box. 
perceived by offspring in their nest according to their nestling conditions (hole nesters vs open nesters).

\section{Mobbing calls recognition and associative learning in fledglings}

Fledglings exhibited a higher rate of scanning when hearing the associative learning stimulus but only if it was associated with mobbing calls during the nestling phase. A similar trend was also observed for calling activity and the propensity to move. Together, these results indicate that individuals associated the artificial sound with conspecific mobbing calls without having to see the mobbing scene. Scanning rate is a good proxy of vigilance effort (Lendrem 1983; Huang et al. 2012; Creel et al. 2014) suggesting that chicks actually perceived the associative learning stimulus as an indicator of threat proximity only if it was associated with mobbing calls during the learning phase. Whether fledglings associated the artificial stimulus as the source of threat itself or as heterospecific mobbing calls (indicating the presence of a threat) and whether the ontogeny of mobbing behaviour only relies on learning processes, remain open questions. Positive correlation between the rate of response development and the magnitude of exposure to heterospecific alarm calls suggest a learning process. For instance, infant vervet monkeys (Cercopithecus aethiops pygerythrus) develop responses to superb starling (Lamprotornis superbus) mobbing calls more quickly on territories where these birds are common, suggesting that these young have more opportunities to learn about the calls than young on territories where starlings are less common (Hauser 1988). Concerning adults, they can associate novel sounds with a chorus of conspecific and heterospecific aerial alarm calls (Potvin et al. 2018). One may thus expect that a learning process where individuals associate the threat and/or heterospecific mobbing calls with the conspecific mobbing calls can operate in the wild. Such mechanisms could make the set of recognized heterospecific mobbing calls 
adjusted to the local composition of prey communities, which is also congruent with field studies reporting local variations of the rate of responses towards heterospecific mobbing calls (Wheatcroft and Price 2013).

In addition to such associative learning processes, our study also reveals that

fledglings responded to conspecific mobbing calls despite the treatment they experienced. Indeed, in both groups, hearing conspecific mobbing calls resulted in increased vigilance, a higher proneness to call as well as to move. Since all these tests were performed on fledging day, we can safely assume that no fledgling could have had the opportunity to observe a mobbing scene before the tests. Our results therefore indicate that fledglings do not need to observe mobbing events to respond to mobbing calls, suggesting that conspecific mobbing calls are inherently perceived as indicating a threat. However, two hypotheses, not mutually exclusive, could explain the responses to mobbing calls: the response (1) is at least partly innate, this result has been found in adult great tits in response to allopatric mobbing calls (Randler 2012, Dutour et al. 2017b), or (2) is due to the impregnation of acoustic signals heard during the nestling phase. Mobbing calls are composed of frequency modulated elements, which are involved in vigilance, and D notes involved in foraging flocks or to recruit partners during the breeding season, to which receivers respond by approaching the caller (Dutour et al. 2019). In the present study, tests were performed during fledgling when great tits form family groups and often use D notes to maintain group cohesion (Dutour, pers. observation). The responses of fledglings could be related to the context (i.e., presence of family members in the vicinity), or could be due to sensitivity to the D notes. Furthermore, contrary to fledglings belonging to the control group, those belonging to the experimental group were more prone to flee than approach the loudspeaker. It could be from the playbacks which were always presented to fledglings in the same order (i.e., associative learning sound, then mobbing calls), creating biases that differed between treatments. Indeed, this could be a 
carry-over from the experimental group hearing the unfamiliar sound, which is threatening to them, before mobbing calls, while the control group heard a non-threatening sound and then the mobbing calls. The situation seemed more dangerous for the experimental group if the two cues had an additive effect. However, this result suggests that reinforcement with mobbing calls during the nestling phase altered mobbing learning. Such impairment could be either due to call overexposure, as previously shown in vocalization learning (Tchernichovski et al. 1999; Brainard and Doupe 2013), or because of the absence of a threat associated with the mobbing call during exposure. An alternative explanation is that maybe fleeing is the adaptive response to mobbing calls for young juveniles. This should be addressed in further studies. It would be feasible in relatively resident birds like great tits where dispersal distances are small. Flee would not be an impairment when expressed by a young, inexperienced, and physically clumsy individual compared with more experienced, agile and older juveniles ( 120 days post fledging) (Kullberg \& Lind, 2002) or adults. In that case, being exposed to additional mobbing via playbacks may have sped up the development of this response.

\section{Conclusion}

This study shows that nestling great tits do not discriminate between two different acoustic signals but demonstrates that they associate mobbing calls with a novel sound when exiting the nest cavity as fledglings. Nevertheless, fledglings did not respond with typical mobbing behaviour (i.e., approach and harass), which likely require experience of parental visual response (i.e., cultural transmission) (Kullberg and Lind 2002). The present findings raise questions about how nestlings extract information about the nature of predators and how finely they can discriminate between different acoustic stimuli. 


\section{References}

Barati A, McDonald PG (2017) Nestlings reduce their predation risk by attending to predatorinformation encoded within conspecific alarm calls. Sci Reps 7:11736. https://doi.org/10.1038/s41598-017-11528-y

Bates D, Maechler M, Bolker B, Walker S (2014) lme4: Linear mixed-effects models using Eigen and S4. R package version 1.1-7. http:// CRAN.R-project.org/package=lme4

Brainard MS, Doupe AJ (2013) Translating birdsong: songbirds as a model for basic and applied medical research. Annu Rev Neurosci 36:489-517. https://doi.org/10.1146/annurev-neuro-060909-152826

Carlson NV, Healy SD, Templeton CN (2017a) A comparative study of how British tits encode predator threat in their mobbing calls. Anim Behav 125:77-92. https://doi.org/10.1016/j.anbehav.2017.01.011

Carlson NV, Pargeter HM, Templeton CN (2017b) Sparrowhawk movement, calling, and presence of dead conspecifics differentially impact blue tit (Cyanistes caeruleus) vocal and behavioral mobbing responses. Behav Ecol Sociol 71:133. https://doi.org/10.1007/s00265-017-2361-X

Cole EF, Cram DL, Quinn JL (2011) Individual variation in spontaneous problem-solving performance among wild great tits. Anim Behav 81:491-498. https://doi.org/10.1016/j.anbehav.2010.11.025

Creel S, Schuette P, Christianson D (2014) Effects of predation risk on group size, vigilance, and foraging behavior in an African ungulate community. Behav Ecol 25:773-784. https://doi.org/10.1093/beheco/aru050

Curio E (1978) The adaptive significance of avian mobbing. I. Teleonomic hypotheses and predictions. Z Tierpsychol 48:175-183. https://doi.org/10.1111/j.14390310.1978.tb00254.x 
Curio E, Ernst U, Vieth W (1978a) Cultural transmission of enemy recognition: one function of mobbing. Science 202:899-901. https://doi.org/10.1111/j.1439-0310.1978.tb00255.x

Curio E, Ernst U, Vieth W (1978b) The adaptive significance of avian mobbing. II. Cultural transmission of enemy recognition in blackbirds: effectiveness and some constraints. $\mathrm{Z}$ Tierpsychol 48:184-202. https://doi.org/10.1126/science.202.4370.899

Davies NB, Brooke MD (1988) Cuckoos versus reed warblers: adaptations and counteradaptations. Anim Behav 36:262-284. https://doi.org/10.1016/S00033472(88)80269-0

Davies NB, Madden JR, Butchart SHM (2004) Learning fine-tunes a specific response of nestlings to the parental alarm calls of their own species. Proc R Soc Lond B Biol Sci 271:2297-2304. https://doi.org/10.1098/rspb.2004.2835

Dutour M, Lena JP, Lengagne T (2016) Mobbing behaviour varies according to predator dangerousness and occurrence. Anim Behav 119:119-124. http:// dx.doi.org/10.1016/j.anbehav.2016.06.024

Dutour M, Lena JP, Lengagne T (2017a) Mobbing behaviour in a passerine community increases with prevalence in predator diet. Ibis 159:324-330. http://dx.doi.org/10.1111/ibi.12461

Dutour M, Léna JP, Lengagne T (2017b) Mobbing calls: a signal transcending species boundaries. Anim Behav 131:3-11. https://doi.org/10.1016/j.anbehav.2017.07.004

Dutour M, Lengagne T, Léna JP (2019) Syntax manipulation changes perception of mobbing call sequences across passerine species. Ethology. https://doi.org/10.1111/eth.12915

Exnerová A, Štys P, Fučíková E, Veselá S, Svádová K, Prokopová M, ... Landová E (2006) Avoidance of aposematic prey in European tits (Paridae): learned or innate?. Behav Ecol 18:148-156. https://doi.org/10.1093/beheco/ar1061 
Ferrari MCO, Chivers DP (2011) Learning about non-predators and safe places: the forgotten elements of risk assessment. Anim Cogn 14:309-316. https://doi.org/10.1007/s10071010-0363-4 PMID: 21203793

Griesser M, Suzuki TN (2016) Kinship modulates the attention of naïve individuals to the mobbing behaviour of role models. Anim Behav 112:83-91. https://doi.org/10.1016/j.anbehav.2015.11.020

Griffin AS, Galef Jr BG (2005). Social learning about predators: does timing matter?. Anim Behav 69:669-678.

Griffin AS, Guillette LM, Healy SD (2015) Cognition and personality: an analysis of an emerging field. Trends Ecol Evol 30:207-214. https://doi.org/10.1016/j.tree.2015.01.012

Haff TM, Magrath RD (2012) Learning to listen? Nestling response to heterospecific alarm calls. Anim Behav 84:1401-1410. https://doi.org/10.1016/j.anbehav.2012.09.005

Hartley PHT (1950) An experimental analysis of interspecific recognition. Symp Soc Exp Biol 4:313-336

Hauser MD (1988) How infant vervet monkeys learn to recognize starling alarm calls: the role of experience. Behaviour 105:187-201. https://doi.org/10.1163/156853988X00016

Hollen LI, Radford AN (2009) The development of alarm call behaviour in mammals and birds. Anim Behav 78:791-800. https://doi.org/10.1016/j.anbehav.2009.07.021

Huang P, Sieving KE, St Mary CM (2012) Heterospecific information about predation risk influences exploratory behavior. Behav Ecol 23:463-472. https://doi.org/10.1093/beheco/arr212

Hurlbert SH (1984) Pseudoreplication and the design of ecological field experiments. Ecol Mono 54:187-211. https://doi.org/10.2307/1942661 
Kalb N, Anger F, Randler C (2019) Subtle variations in mobbing calls are predator-specific in great tits (Parus major). Sci Rep-Uk 9:6572. https://doi.org/10.1038/s41598-01943087-9

Kroodsma DE, Byers BE, Goodale E, Johnson S, Liu WC (2001) Pseudoreplication in playback experiments, revisited a decade later. Anim Behav 61:1029-1033. https://doi.org/10.1006/anbe.2000.1676

Kullberg C, Lind J (2002) An experimental study of predator recognition in great tit fledglings. Ethology 108:429-441. https://doi.org/10.1046/j.1439-0310.2002.00786.x

Lendrem DW (1983) Predation risk and vigilance in the blue tit (Parus caeruleus). Behav Ecol Sociol 14:9-13

Lind L, Jöngren F, Nilsson J, Schönberg Alm D, Strandmark A (2005) Information, predation risk and foraging decisions during mobbing in great tits Parus major. Orn Fennica 82:89-96

Madden JR, Kilner RM, Davies NB (2005) Nestling responses to adult food and alarm calls: 1. Species specific responses in two cowbird hosts. Anim Behav 70:619-627. https://doi.org/10.1016/j.anbehav.2004.11.019

Magrath RD, Haff TM, Horn AG, Leonard ML (2010) Calling in the face of danger: how predation risk affects acoustic communication by parent birds and their offspring. Adv Stud Behav 41:187-253. https://doi.org/10.1016/S0065-3454(10)41006-2

Magrath RD, Haff TM, McLachlan JR, Igic B (2015a) Wild birds learn to eavesdrop on heterospecific alarm calls. Curr Biol 25:2047-2050. https://doi.org/10.1016/j.cub.2015.06.028

Magrath RD, Haff TM, Fallow PM, Radford AN (2015b) Eavesdropping on heterospecific alarm calls: from mechanisms to consequences. Biol Rev 90:560-586. https://doi.org/10.1111/brv.12122 
Maloney RF, McLean IG (1995) Historical and experimental learned predator recognition in free-living New Zealand robins. Anim Behav 50:1193-1201. https://doi.org/10.1016/0003-3472(95)80036-0

Marler P (1957) Specific distinctiveness in the communication signals of birds. Behaviour 11:13-38. https://doi.org/10.1163/156853956X00066

McIvor GE, Lee VE, Thornton A (2018) Testing social learning of anti-predator responses in juvenile jackdaws: the importance of accounting for levels of agitation. R Soc Open Sci 5:171571. https://doi.org/10.1098/rsos.171571

McLean IG, Hoelzer C, Studholme BJS (1999) Teaching predator-recognition to a naive bird: implications for management. Biol Conserv 87:123-130. https://doi.org/10.1016/S00063207(98)00024-X

Morand-Ferron J, Hamblin S, Cole EF, Aplin LM, Quinn J L (2015) Taking the operant paradigm into the field: associative learning in wild great tits. PLoS One 10:e0133821. https://doi.org/10.1371/journal.pone.0133821

Perrins CM (1965) Population fluctuations and clutch-size in the Great Tit, Parus major L. J Anim Ecol 601-647. https://doi.org/10.2307/2453

Platzen D, Magrath RD (2004) Parental alarm calls suppress nestling vocalization. Proc R Soc Lond B Biol Sci 271:1271-1276. https://doi.org /10.1098/rspb.2004.2716

Potvin DA, Ratnayake CP, Radford AN, Magrath RD (2018) Birds learn socially to recognize heterospecific alarm calls by acoustic association. Cur Biol 28:2632-2637. https://doi.org/10.1016/j.cub.2018.06.013

Randler C (2012) A possible phylogenetically conserved urgency response of great tits (Parus major) towards allopatric mobbing calls. Behav Ecol Sociobiol 66:675-681. https://doi.org/10.1007/s00265-011-1315-y 
Rydén O (1978) Differential responsiveness of great tit nestlings, Parus major, to natural auditory stimuli. Ethology 47:236-253. https://doi.org/10.1111/j.14390310.1978.tb01834.x

Rydén O (1980) Heart rate response in great tit nestlings (Parus major) to an alarm call. Journal of comparative and physiological psychology, 94:426. http://dx.doi.org/10.1037/h0077680

Schaller GB, Emlen JT (1961) The development of visual discrimination patterns in the crouching reactions of nestling grackles. The Auk 73:125-137

Shettleworth SJ (2010) Cognition, evolution, and behavior. Oxford University Press.

Shriner WM (1999) Antipredator responses to a previously neutral sound by free-living adult golden-mantled ground squirrels, Spermophilus lateralis (Sciuridae). Ethology 105:747-757. https://doi.org/10.1046/j.1439-0310.1999.00454.x

Suzuki TN (2011) Parental alarm calls warn nestlings about different predatory threats. Current Biology 21: R15-R16. https://doi.org/10.1016/j.cub.2010.11.027

Suzuki TN (2012) Referential mobbing calls elicit different predator-searching behaviours in Japanese great tits. Animal Behaviour, 84(1), 53-57. https://doi.org/10.1016/j.anbehav.2012.03.030

Suzuki TN, Wheatcroft D, Griesser M (2016) Experimental evidence for compositional syntax in bird calls. Nat Commun 7:10986. https://doi.org/10.1038/ncomms10986

Suzuki TN, Wheatcroft D, Griesser M (2017) Wild Birds Use an Ordering Rule to Decode Novel Call Sequences. Curr Biol 27:2331-2336. https://doi.org/10.17632/r7v96zf5pp.1

Tchernichovski O, Lints T, Mitra PP, Nottebohm F (1999) Vocal imitation in zebra finches is inversely related to model abundance. Proc Natl Acad Sci U S A 96:12901-12904. https://doi.org/10.1073/pnas.96.22.12901 
578 Wheatcroft D, Price TD (2013) Learning and signal copying facilitate communication among 579 bird species. Proc R Soc Lond B Biol Sci 280:20123070.

580 https://doi.org/10.1098/rspb.2012.3070

581 Wheatcroft, D (2015) Repetition rate of calls used in multiple contexts communicates

582 presence of predators to nestlings and adult birds. Anim Behav, 103, 35-44.

$583 \quad$ https://doi.org/10.1016/j.anbehav.2015.02.009

584 Wheeler BC, FahyM, Barbara Tiddi (2019) Experimental evidence for heterospecific alarm

585 signal recognition via associative learning in wild capuchin monkeys. Anim Cogn, 1-9.

586 https://doi.org/10.1007/s10071-019-01264-3 
607

Acknowledgments We warmly thank the "Fondation Pierre Vérots" (PVF) for giving us access to the field site. We are indebted to JP Rabatel (PVF) for his assistance. We express our gratitude to several students who assisted with the field work. We are grateful to Bernard Kaufmann for English corrections. We thank the editor, Christoph Randler, and anonymous reviewers for constructive comments on an earlier version of this manuscript.

Funding This work was supported by French Ministry of Research and Higher Education funding (to M.D. PhD grants 2015-2018).

\section{Compliance with ethical standards}

Conflict of interest The authors declare that they have no conflict of interest.

Ethics approval Our work was carried out under permission from the Prefecture du Rhône (Ref 2015-13), Prefecture de l'Ain (DDPP01-15-230) and with the approval of the ethics committee at Lyon 1 University, France (permit number: 2017012410184917). All authors are accredited for performing experiments with living animals (French diploma "Experimentation animale" first level for researchers). After ringing, all nestlings were readily accepted back by their parents.

Human and animal rights This article does not contain any studies with human participants performed by any of the authors. 
610 Generalized linear mixed models (GLMM) results for playback (associative learning stimulus

611 or mobbing calls) and group (experimental or control) as predictors of variation in fledglings

612 response behaviours (scanning, calling, approaching + fleeing). The “*” character indicates

613 the interaction between the explanatory terms. Significant $\mathrm{P}$ values are indicated in bold.

\begin{tabular}{llccc}
\hline Behaviours & Fixed effects & df & $\chi^{2}$ & $P$ \\
\hline scanning & playback & 1 & 5.8243 & $\mathbf{0 . 0 1 5 8}$ \\
& group & 1 & 6.1785 & $\mathbf{0 . 0 1 2 9}$ \\
& playback*group & 1 & 5.4487 & $\mathbf{0 . 0 1 9 6}$ \\
calling & playback & 1 & 0.9227 & 0.3368 \\
& group & 1 & 0.0247 & 0.8752 \\
& playback*group & 1 & 4.8979 & $\mathbf{0 . 0 2 6 9}$ \\
playback & 1 & 8.9545 & $\mathbf{0 . 0 0 2 8}$ \\
& group & 1 & 1.6161 & 0.2036 \\
& playback*group & 1 & 0.8797 & 0.3483 \\
\hline
\end{tabular}

614 
618 Fig. 1 Number of horizontal scans made by experimental and control fledglings during the

619 playbacks of associative learning stimulus and mobbing calls (mean $\pm \mathrm{SE}$ )

620

621 Fig. 2 Experimental and control fledglings' probability of calling during playbacks of 622 associative learning stimulus and mobbing calls

623

624 Fig. 3 Response of experimental and control fledglings to playbacks of associative learning 625 stimulus (white) and mobbing calls (grey) 